\title{
A Tale of 2 Countries: The Cost of My Mother's Cardiac Care in the United States and India
}

\author{
Sowmya R. Rao, PbD \\ Department of Quantitative Health Sci- \\ ences, University of Massachusetts Medical \\ School, Worcester, Massachusetts \\ Center for Healthcare Organization \\ and Implementation Research (CHOIR), \\ Bedford VA Medical Center, Bedford, \\ Massachusetts
}

\begin{abstract}
When my mother fell ill while visiting me in the United States, I had the opportunity to compare costs of surgical cardiac care in the United States and India. I faced challenges in making well-informed decisions in the United States due to the lack of cost transparency and the minimal flexibility offered in choice of care, whereas in India costs are readily available and allow most people to freely choose their preferred type of care.
\end{abstract}

Ann Fam Med 2014;12:470-472. doi: 10.1370/afm.1676.

Thave lived in the United States for more than 20 years and am part of the health services research community that investigates factors behind the rising costs of health care. After seeking medical care for my mother in both the United States and India, however, I was surprised to find that "developed" countries have a lot to learn from some of the ways health care is delivered in "developing" countries. This essay describes the stark differences in the organization and financing of health care services that my family recently experienced, and how those differences affected our ability to make important health care decisions.

\section{US EXPERIENCE}

My mother, a 71-year-old, fit, active woman, arrived in Boston from Bangalore, India, in June 2013 for a 4 -month visit. Soon after her arrival, when walking in our neighborhood, she felt a momentary tightness in her chest that disappeared when she stopped walking. She had a few more such episodes over the next few days, and although she did not complain of pain or shortness of breath, I decided to be safe and schedule a medical checkup.

I approached my longtime primary care physician first. He refused to provide services, saying "it could get very involved if it is a cardiac issue. She might have to go to the hospital..." I could have paid for the services, but he did not discuss payment and offered no alternative suggestions.

Next, I contacted a friend, an interventional cardiologist at a leading teaching hospital in the region, who examined my mother, ordered blood tests and electrocardiography, and recommended her to a clinical study that randomized patients to cardiac computed tomography (CT) or stress test. She ended up in the CT arm. The scan showed severe blockages in the coronary arteries; angiography was recommended. The choice of further treatment, either stents or coronary artery bypass graft (CABG) surgery, depended on the catheterization results.

I contacted the hospital's international office, which helps international patients navigate the intricacies of the US health care system. I hoped the international office would help me understand the process for getting my mother the recommended procedure, including costs. After a week, I was presented with an average estimate of $\$ 47,000$ (average hospital charges of $\$ 38,500$, estimated professional fees of $\$ 7,700$, and a mandatory state uncompensated care pool surcharge of \$728) for an inpatient cardiac catheterization for someone requiring only 1 stent and an overnight stay in a 
semiprivate room. The international office specified that "the estimate DOES NOT include Surgeon Fees, Private Room Accommodations, or any other Medical Services, Testing and Treatments that may be needed," so I was left with no idea what the total charges might be or how different scenarios (eg, requesting a private room) would affect the cost. Moreover, the catheterization would be conducted only if a written insurance authorization was provided or the full estimated payment was credited to the hospital's bank 5 days before my mother received care.

My mother had traveler's insurance from an Indian company with ties to a US company that would have compensated for services up to a certain amount, but they hesitated to approve the procedure without fully knowing the final charges. The insurance company eventually declined to cover the treatment due to "patient history" (the insurance company's terminology). Having no idea of how high the costs might go, we could not commit to paying the costs ourselves.

\section{INDIA EXPERIENCE}

After 6 weeks of trying to obtain care for my mother in the United States, we left for Bangalore. A few days later, she had a cardiac catheterization with a respected interventional cardiologist at a cardiac specialty hospital. The cost, including a 1-day hospital stay, was 16,500 Indian Rupees (approximately $\$ 254$ US at the time). The scan showed multiple blockages needing either 3 metal stents or CABG surgery. Given her preexisting diabetes, it was likely that CABG surgery was the best option. An interventional cardiologist at another cardiac care hospital agreed.

The cardiovascular and thoracic surgeons deemed her fit enough for the triple bypass and immediately scheduled the procedure. She was admitted 1 day before the surgery for pre-operative testing.

We met with billing staff the day we scheduled the surgery and obtained an estimate that nearly matched the final cost. The process was very simple and quick. All costs were tiered to the type of room the patient selected-general ward (consisting of 5 to 10 beds), semiprivate, private, or deluxe room. Patients in deluxe rooms paid the most, subsidizing costs for patients in the general ward, who paid the least. The hospital informed us that all patients received identical care; that is, the same team of doctors worked with all patients and staff and gave them similar attention. Coincidentally, we met 2 other families with relatives who had had CABG surgery and were in the intensive care unit (ICU). One had opted for a semi-private room while the other had selected the general ward. Both families were satisfied with the attention and care received.
For every inpatient procedure at the hospital in Bangalore, the patient is required to stay for a certain number of days; thus, hospitals have packages (for instance, 3 - or 5-day stays). My mother had a 7-day package stay in a private room. The billing department told us the cost of a basic package with estimates of additional costs for surgical disposables (including use of an auto transfusion machine), any additional stay in the ICU or the room, and visits by other specialists. Surprisingly, CABG surgery in India is cheaper than stenting; the stents themselves are expensive. The basic package for CABG surgery was estimated at 279,000 Rupees (about $\$ 4,300$ ), in contrast, remember that the US estimate for catheterization with one stent was $\$ 47,000$.

My mother's 7-day stay included 5 days in her private room after 1.5 to 2 days in the ICU following surgery. The entire team of 2 surgeons, 3 endocrinologists, an anesthesiologist, a physiotherapist, and a dietician visited her daily, both before and after surgery. All food provided by the hospital was ordered by their dietician. The ICU was staffed at a ratio of 1 nurse for every patient but because there were only 2 patients in the ICU during her stay, she had up to 5 nurses attending to her.

My mother's basic Indian health insurance policy covered $80 \%$ of her expenses up to 100,000 Rupees. In addition to that 80,000 Rupees, she received 40,000 rupees from another company with which she had 200,000 Rupees additional insurance for procedures such as CABG. Since her basic insurance had negotiated rates with the hospital, her total bill was reduced to 230,000 Rupees (about $\$ 3,540$ ). With the 120,000 Rupees in insurance payments, that meant that her outof-pocket expense was only 110,000 Rupees $(\$ 1,700)$. In contrast, we paid approximately $\$ 1,000$ (including $\$ 700$ in facility charges) for her 1 visit to the cardiologist and blood work at the US hospital.

\section{REFLECTIONS}

The information available in the United States did not allow us to make an informed decision. Patients cannot make decisions based on out-of-pocket costs in the United States, because US costs are not transparent. In contrast, the simpler Indian model of having a basic estimate for the procedure and type of room chosen, with add-ons for complications, made accurate financial planning possible. Another benefit of the Indian health care system was the flexibility it offered in choosing the hospital, doctor, procedure type, and type of room. In the United States, this flexibility is limited by type of insurance coverage. In India, for that matter, persons from the upper middle-class (based on income) can 
afford to self-pay for medical care (including CABG surgery), even without health insurance.

In retrospect, seeking treatment in India, with an average Gross Domestic Product less than one-eighth that of the United States, ${ }_{1}^{1}$ was the right decision. Cardiac specialty care in India is world-class, with success and morbidity rates similar to those in developed countries $^{2}$; India is working to further reduce costs. ${ }^{3,4}$

My mother has fully recovered and is doing well. Her experience shows that the United States could benefit from an important lesson learned in this case study: that increased transparency in health care costs is essential for choosing not only the hospital and provider of care, but also the appropriate course of action.

To read or post commentaries in response to this article, see it online at http://www.annfammed.org/content/12/5/470.

Key words: international perspectives; health care financing; pricing; health insurance

Submitted December 12, 2013; submitted, revised April 17, 2014; accepted May 6, 2014.
Disclaimer: The opinions expressed in this manuscript do not necessarily represent the official views of the Department of Veterans Affairs.

Acknowledgments: I thank my husband, Dr David S. Morgan; my sisters, Sukanya Rao and Sandhya Rao; my brothers-in-law, T.S. Gururaj and Jay Srinivasan; my niece, Malavika Gururaj; and my colleagues, Dr Amy Rosen, Dr Arlene Ash and Beth Ann Petrakis for their invaluable support and help in the preparation of this manuscript.

\section{References}

1. The World Bank. GDP (current US\$). http://data.worldbank.org/indicator/NY.GDP.MKTP.CD. Accessed Dec 8, 2013.

2. Cardiac care in India. Global Health and Travel. 2011. http://www. globalhealthandtravel.com/medical_care/CardiacCareinlndia. Published August 20, 2011. Accessed Dec 8, 2013.

3. Gokhale K. Heart surgery in India for $\$ 1,583$ costs $\$ 106,385$ in U.S. Bloomberg. July 28, 2013. http://www.bloomberg.com/news/201307-28/heart-surgery-in-india-for-1-583-costs-106-385-in-u-s-.html. Accessed Dec 8, 2013.

4. Govindarajan, V. Indian hospitals could show U.S. hospitals how to save money without cutting quality. Washington Post. November 1, 2013. http://www.washingtonpost.com/opinions/indian-hospitalscould-show-us-hospitals-how-to-save-money-without-cuttingquality/2013/11/01/d02c8e58-3c28-11e3-b7ba-503fb5822c3e_story. html. Accessed Dec 8, 2013.

\section{Get the Annals of Family Medicine by E-mail}

Make sure you see every new issue

while it's fresh; have the table of

contents sent to you by e-mail for

easy access to articles of interest.

Don't miss important research.

Request the e-mail table of contents at

http://lyris.aafp.org/subscribe/annals/.

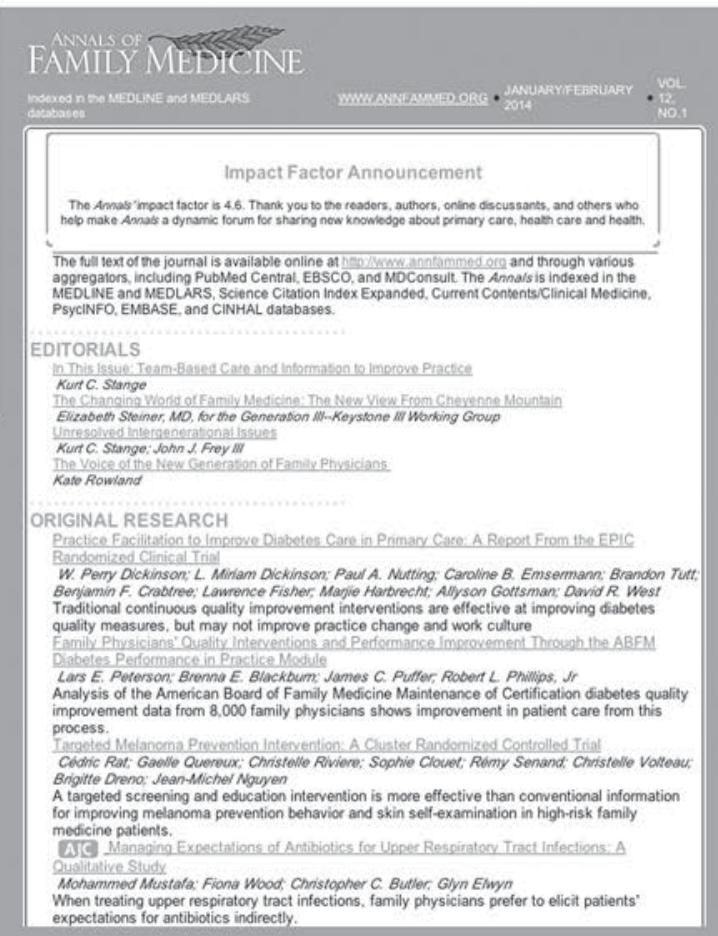

